\title{
Disease in the Elderly
}

\section{Severe renal sepsis in the very elderly}

\author{
J. P. Milnes and D. G. Swain
}

Department of Geriatric Medicine, East Birmingham Hospital, Birmingham B9 5ST, UK.

\begin{abstract}
Summary: We describe three cases of severe renal sepsis in the very elderly and discuss the diagnostic pitfalls.
\end{abstract}

\section{Introduction}

Significant bacteriuria (SB) is a common finding in the very elderly. It is often asymptomatic, and the routine use of antibiotics remains controversial (Sourander, 1978). Occasionally, however, SB may be an indicator of serious and unsuspected renal infection. Three cases are described to illustrate the difficulties in diagnosis posed by very elderly patients with severe renal sepsis.

\section{Case reports}

\section{Case 1}

An 85 year old man was admitted to hospital with a one year history of anorexia and weight loss, and recent falls. He was unsteady on walking, but physical examination was otherwise unremarkable. Shortly after admission he suffered a rigor.

Initial blood investigations showed haemoglobin $10.0 \mathrm{~g} / \mathrm{dl}$, white cell count (WBC) $20.4 \times 10^{9} / 1$, urea $11.8 \mathrm{mmol} / 1$ and creatinine $210 \mu \mathrm{mol} / \mathrm{l}$. Chest X-ray was normal but urine culture isolated Escherichia coli $>10^{5}$ organisms $/ \mathrm{ml}$. His condition improved following treatment with ampicillin, and repeat urine culture was sterile.

A low grade pyrexia persisted, but a plain abdominal X-ray and ultrasound examination of the urinary tract were normal. He then deteriorated with an $E$. coli septicaemia, and subsequently developed pyramidal signs in both legs and became ataxic. Intracerebral sepsis was suspected, but computerized tomography (CT) demonstrated only cortical atrophy. Following antibiotic treatment he became

Correspondence: J. P. Milnes, M.R.C.P., Division of Medicine, Selly Oak Hospital, Raddlebarn Road, Selly Oak, Birmingham B29 6JD

Accepted: 6 February 1986 apyrexial, and his WBC and blood urea returned to normal. However he remained anaemic with an elevated erythrocyte sedimentation rate, and whilst undergoing further investigations he developed a bronchopneumonia and died.

A post-mortem examination demonstrated a right sided pyonephrosis and perinephric abscess, and a subdural abscess from which $E$. coli was isolated.

\section{Case 2}

An 80 year old woman was admitted to hospital with a 3 week history of constipation and abdominal pain, and one week of dysuria. She suffered from ischaemic heart disease, obesity, hypertension, glaucoma and macular degeneration. On examination she was drowsy and dehydrated with diffuse abdominal tenderness.

Initial blood investigations showed WBC $8.6 \times 10^{9} / 1$ and urea $19.8 \mathrm{mmol} / \mathrm{l}$. Urine culture isolated Proteus mirabilis $>10^{5}$ organisms $/ \mathrm{ml}$.

She improved following treatment with fluids, an antibiotic and laxatives. Her recovery was complicated by a deep venous thrombosis, an episode of acute cholecystitis and pneumonia. On discharge her blood urea and creatinine were normal.

She was subsequently catheterized to control her urinary incontinence, and had further hospital admissions for respite care and two episodes of pyelonephritis. Both infective episodes responded promptly to antibiotic treatment. Following therapy for the second infection her WBC and creatinine level returned to normal. However as discharge plans were being finalized she acutely developed abdominal pain, and died shortly afterwards.

A post-mortem examination demonstrated urinary calculi in the bladder and right renal pelvis. The latter was pus-filled with a direct tract into a large perinephric abscess surrounded by an extensive cellulitis.

(C) The Fellowship of Postgraduate Medicine, 1986 


\section{Case 3}

An 85 year old woman was admitted to hospital following a fall. She was a diabetic controlled on diet and gliclazide. She was found to be dehydrated and unsteady on walking.

Initial blood investigations showed WBC $10.7 \times 10^{9} / 1$, urea $16.7 \mathrm{mmol} / \mathrm{l}$ and glucose $16.2 \mathrm{mmol} / \mathrm{l}$.

Her blood glucose steadily rose necessitating treatment with intravenous fluids and insulin. Urine culture isolated $E$. coli $>10^{5}$ organisms $/ \mathrm{ml}$, and despite the absence of pyrexia and urinary symptoms this was treated with intravenous cefuroxime followed by oral cephalexin. She improved and repeat urine culture was sterile.

Her diabetes remained difficult to control and she became very confused. Two weeks following admission she suddenly died.

A post-mortem examination showed extensive bilateral pyelonephritis with micro-abscess formation.

\section{Discussion}

Some of the problems encountered in the diagnosis of renal infection in old age are recognized (Sourander, 1978). We feel, however, that the particular difficulties posed by very elderly people with serious renal infection warrant special attention.

In general, severe renal sepsis is associated with SB. The latter is usually defined as a bacterial count of more than $10^{5}$ organisms $/ \mathrm{ml}$ of clean, freshly voided urine, and its prevalence rises with increasing age.

Published prevalence figures clearly demonstrate that SB is a common finding in the very elderly (Table I). The variation between series reflects the size and nature of the population studied, and the criteria used for the diagnosis of SB and contaminated specimens.

SB is a fluctuating condition (Brocklehurst et al., 1977). In the 5 year follow-up of the community survey of people aged over 65 years by Sourander et al. (1970), 35\% of the survivors who had had SB 5 years previously remained infected. New infections had developed in $7 \%$ of males and $13 \%$ of females. Suntharalingham et al. (1983) have demonstrated that, contrary to standard teaching, the infection is often renal.

The occurrence of SB appears to correlate with a deterioration in general health, and in a study of the healthy residents from a home for the aged was associated with a significant decrease in survival (Dontas et al., 1981). Despite this, SB is often asymptomatic, does not usually require further investigations, and the routine use of antibiotics remains controversial.

Age-related changes, especially the decline in renal function, affect the interpretation of blood urea and creatinine values. The reference range for blood urea rises from $3.2-7.2 \mathrm{mmol} / 1$ in young adults to $3.9-9.9 \mathrm{mmol} / 1$ in old age, and the values for creatinine from $62-123 \mu \mathrm{mol} / 1$ to $52-159 \mu \mathrm{mol} / 1$ (Hodkinson, 1983).

In the three cases described urinary symptoms, pyrexia and neutrophilia were often absent in the presence of severe renal sepsis. A seemingly good response to antibiotic treatment can be misleading, and there may also be a temptation to give an inappropriately low dosage as the clinical impression may be that of only minor illness.

Case 2 suffered from multiple pathologies and became increasingly frail whilst under our care. Her poor general condition put her at major risk from elective surgery, so further investigation was noto pursued, especially as she had responded promptly to antibiotic therapy on each occasion. In contrast, inô case 1 the apparently good response to antibiotic? therapy, and the likelihood of multiple pathologies, prevented more invasive investigations despite the correct clinical suspicion. Neurosurgeons are aware that on clinical suspicion of subdural abscess, patients may have to be explored even in the presence of a normal CT scan (Bannister et al., 1981).

Choice of investigations raises important issues. Ultrasound examination of the urinary tract, together with a plain abdominal X-ray is reliable in excluding hydronephrosis (Editorial, 1984), and this combination will often confirm the presence of urinary calculi. Ultrasonography, however, cannot duplicate the fine detail obtained by intravenous urography (Schneider et al., 1976), and furthermore it does have major

Table I The prevalence of significant bacteriuria in the very elderly

\begin{tabular}{|c|c|c|c|c|}
\hline Study & Population & Age (years) & Male & Female \\
\hline Akhtar et al.(1972) & Community study & 80 and over & $9 \dagger$ & 20 \\
\hline Brocklehurst et al. (1968) & Community study & over 80 & 21 & 23 \\
\hline Hagenfeldt et al. (1962) & Acute medical admissions & over 80 & 14 & 35 \\
\hline Sourander (1966) & Community study & over 80 & 22 & 50 \\
\hline Walkey et al. (1967) & Acute geriatric admissions & 80 and over & 29 & 35 \\
\hline
\end{tabular}

$\dagger$ The figures are percentages of the population studied. 
limitations in the diagnosis of renal infection (Brooke Jeffrey et al., 1985; Hoddick et al., 1983: Schneider et al., 1976). In the appropriate clinical setting further investigation may be necessary.

The decision as to how far to pursue our clinical suspicions, especially if invasive tests are necessary, can pose a major dilemma when managing a very elderly patient, and perhaps we can be too easily reassured by negative investigations.

In conclusion, severe renal infection must be considered as a treatable cause of deterioration in a very elderly patient. The finding of SB may be one of the few clues. Many factors combine to cause diagnostic difficulty: the non-specific or atypical presentation of

\section{References}

AKHTAR, A.J., ANDREWS, G.R., CAIRD, F.I. \& FALLON, R.J. (1972). Urinary tract infection in the elderly: a population study. Age and Ageing, 1, 48.

BANNISTER, G., WILLIAMS, B. \& SMITH, S. (1981). Treatment of subdural empyema. Journal of Neurosurgery, 55, 82.

BROCKLEHURST, J.C., BEE, P., JONES, D. \& PALMER, M.K. (1977). Bacteriuria in geriatric hospital patients; its correlates and management. Age and Ageing, 6, 240.

BROCKLEHURST, J.C., DILLANE, J.B., GRIFFITHS, L. \& FRY, J. (1968). The prevalence and symptomatology of urinary infection in an aged population. Gerontologia Clinica, 10, 242.

BROOKE JEFFREY, R., LAING, F.C., WING, V.W. \& HODDICK, W. (1985). Sensitivity of sonography in pyonephrosis: a re-evaluation. American Journal of Roentgenology, 144, 71.

DONTAS, A.S., KASVIKI-CHARVATI, P., PAPANAYIOUTOU, P.C. \& MARKETOS, S.G. (1981). Bacteriuria and survival in old age. New England Journal of Medicine, 304, 939.

EDITORIAL (1984). Diagnosing obstruction in renal failure. Lancet, ii, 848.

HAGENFELDT, L., WESTER, P.O., LITHANDER, A. \& ELIASH, H. (1962). The incidence of urinary tract infection in hospitalised patients. Scandinavian Journal of Clinical and Laboratory Investigation, Supplement, 64, 77. disease, partially-treated infection, the common occurrence of SB in extreme old age, misinterpretation of tests due to multiple pathologies and age related changes, the dilemma of how extensively to investigate very old and often very frail people, and finally we should not forget the practical difficulty in obtaining clean urine specimens.

\section{Acknowledgments}

We thank Dr R.M. Kamalarajan for giving us permission to report the cases and Mrs R. Williams and Miss J. Cooper for typing the manuscripts.

HODDICK, W., BROOKE JEFFREY, R., GOLDBERG, H.I., FEDERLE, M.P. \& LAING, F.C. (1983). CT and sonography of severe renal and perirenal infections. American Journal of Roentgenology, 140, 517.

HODKINSON, M. (1983). Biochemical changes in old age. Medicine International, 1, 1701.

SCHNEIDER, M., BECKER, J.A., STAIANO, S. \& CAMPOS, E. (1976). Sonographic-radiographic correlation of renal and perirenal infections. American Journal of Roentgenology, $127,1007$.

SOURANDER, L.B. (1966). Urinary tract infection in the aged: an epidemiological study. Annales Mediciniae Internae Fenniae, 55, Suppl. 45.

SOURANDER, L.B. (1978). In Textbook of Geriatric Medicine and Gerontology, Brocklehurst, J.C. (ed). p. 294 and 301, Churchill Livingstone: London.

SOURANDER, L.B., RUIKKA, I. \& KASANEN, A. (1970). A health survey on the aged with a 5-year follow-up. Acta Sociomedica Scandinavica. Supplement 3.

SUNTHARALINGHAM, M., SETH, V. \& MOORE-SMITH, B. (1983). Site of urinary tract infection in elderly women admitted to an acute geriatric assessment unit. Age and Ageing, 12, 317.

WALKEY, F.A., JUDGE, T.G., THOMPSON, J. \& SARKARI, N.B.S. (1967). Incidence of urinary infection in the elderly. Scottish Medical Journal, 12, 411. 